\title{
Defect analysis of bearings with vibration monitoring and optical methods
}

\author{
K. DEAK, J. MENYhÁRT, L. CZÉGÉ \\ University of Debrecen, Faculty of Engineering, Department of Mechanical Engineering, \\ deak.krisztian@eng.unideb.hu \\ University of Debrecen, Faculty of Engineering, Department of Mechanical Engineering, \\ jozsef.menyhart@eng.unideb.hu \\ University of Debrecen, Faculty of Engineering, Department of Mechanical Engineering, \\ czege.levente@eng.unideb.hu
}

Diagnosis of bearings with advanced methods gained remarkable roles in the previous years. This article focuses on the manufacturing defects and methods to reveal and classify them. During manufacturing several faults could emerge because of the grinding operation, tool wear and chatter vibration. Inproper handling of the bearing parts because of the collosion to each other and the storing box that causes deformation. To reveal these problems several methods are applied in industry. For deeper surface analysis nitric acid can be used to initate the finished surface of the roller then natrium-carbonate that nautralize the elements. Vibration analysis in its standard Fourier form is not a new achivement but other mathematical tools could be applied to condition monitoring such as wavelet transform. It is an efficient tool for analyzing the vibration signal of the bearings because it can detect the sudden changes and transient impulses in the signal caused by faults on the bearing elements. In this article five different wavelets, Daubechies, Gaussian, Coiflet, Mexican hat, Meyer are compared according to the Energy to Shannon Entropy ratio criteria to reveal their efficiency for fault detection.

\section{Introduction}

Patel et al. used envelope methods to reveal local faults on the races of deep groove ball bearings [1]. Kalman and $\mathrm{H}$ filter were applied by Khanam et al. to measure bearing faults especially in noisy condition with low signal-to-noise ratio when it was difficult to identify the useful components of the vibration signal [2]. Some studies used acoustic signal instead of vibration to indentify bearing faults $[3,4]$. Acoustic emission measurement is a powerful method to detect cracks inside the bearing material which are the initial reasons of fatigue spallings Al-Ghamd and Mba applied this method combined with the traditional vibration analysis to determine the bearing outer race defect width directly from the raw signal [3]. Sawalhi and Randall made their researches to determine the fault size of the bearings from the vibration signal by analyzing the entry and exit impulses [5].

Because of its flexibility and computational efficiency several studies applied the wavelet analysis in bearing fault diagnosis [7-12]. Wavelets are perfect tools for fault feature extraction, singularity detection for signals, denoising and extraction of the weak signals from the vibration signals. These applications were presented by Peng and Chu [6]. Combination of envelope spectrum and wavelet 
transform for extraction of defect problems in bearings were used by Shi et al. [8]. Discrete wavelet transform with Daubechies-4 (db04) mother wavelets to analyze the combination of different faults on the races of ball bearings were used by Prabhakar et al. [7].

Wavelet filter based denoising is suitable method for detection of weak signatures in bearing fault diagnosis. This experiment was presented by Qiu et al. [10]. Symlet wavelets were used efficiently in the study of Kumar et al. [12]. In their study tapered roller bearings were analyzed to determine the fault size on the outer ring.

Symlet wavelets were used in several papers [7-11] to determine the problems of bearings and machines since its shape is adequate to solve the problem. Symlet-5 wavelet represents the entry and impact events as the roller hits the defects during operation of the bearing. A detailed study was presented about the decomposition of the vibration signals using discrete wavelet transform with Symlet-5 by Kumar et al. [14]. Moreover, Symlet wavelet is a good tool for noise reduction in ECG signals because it could filter out the useful components of the complex signal from the noisy background [13].

Analytical Wavelet Transform (AWT) based acoustic emission technique for identifying inner race of radial ball bearing were applied by Kumar et al. [15]. Machine learning methods for optimization of parameteres such as support vector machines were used by Mankovits et al. [16]. Approaches based on simulation using applied methods are analyzed by Szántó et al. [23-24.] where Matlab software are emphasized to find solutions for real appliations. Mankovits et al. applied optimization methods for rubber parts in publications [25-29.] to determine the best shape of rubber parts for different purposes.

\section{Manufacturing faults of bearings}

In this paper we focus on only the technical factors of the process. We do not focus on human and enviromental factors. Remaining useful lifetime is greatly influenced by manufacturing and operational defects.

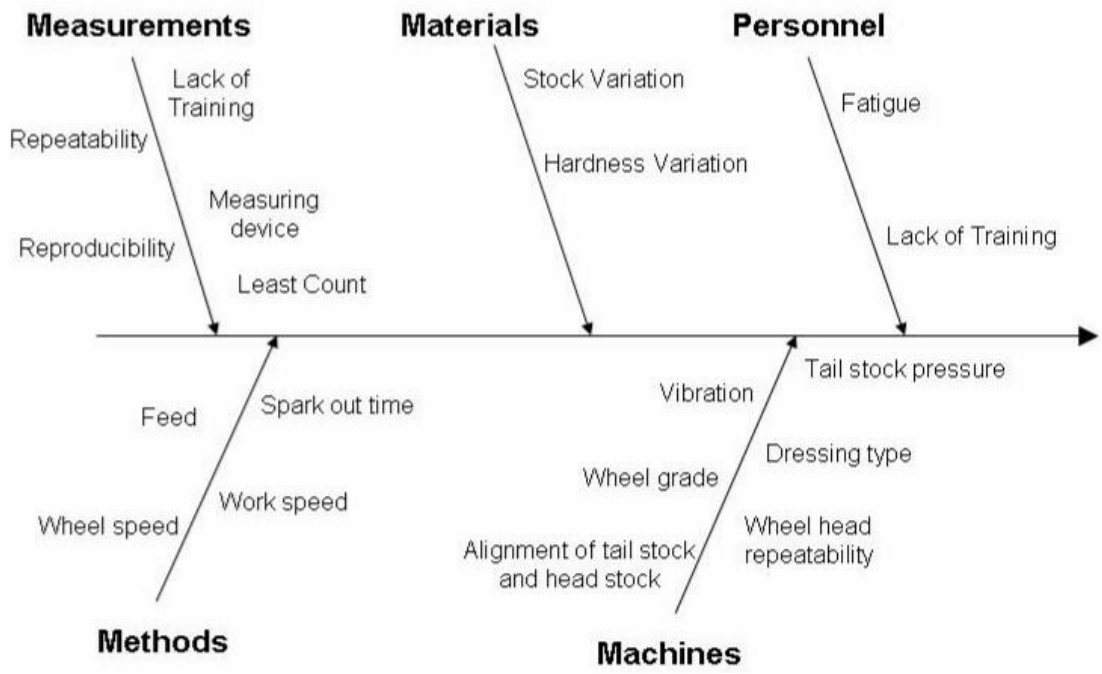

Figure 1. Ishikawa analysis for revealing root causes. 


\subsection{Machine problems}

Grinding problems due to grinding wheel wear process and misaligment of the wheel. Chatter vibration could have source of machining defects as well.

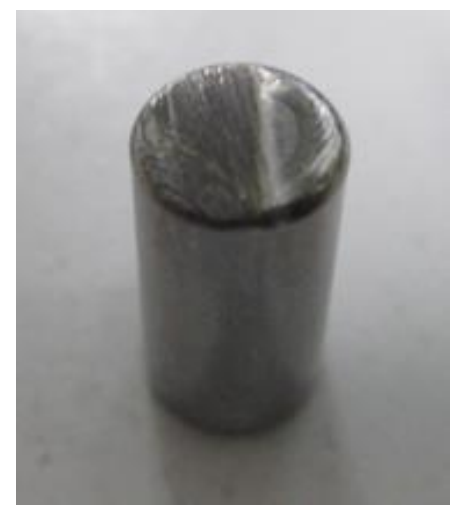

Figure 2. Misgrinded roller.

\subsection{Process and technology problems}

Pulling operation can cause traces on the roller surface which are parallel with the axis of the roller.

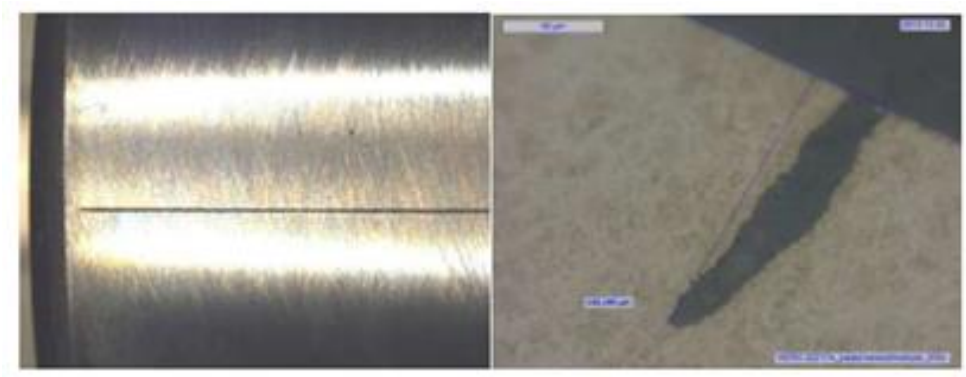

Figure 3. Pulling traces magnified under optical microscope.

Squeezing can cause irregular dents on the roller surfaces. If deburring is not perfect, chips are pressed into the surface causing dents on the roller surfaces. Dents are placed mostly near to the radius of the rollers.
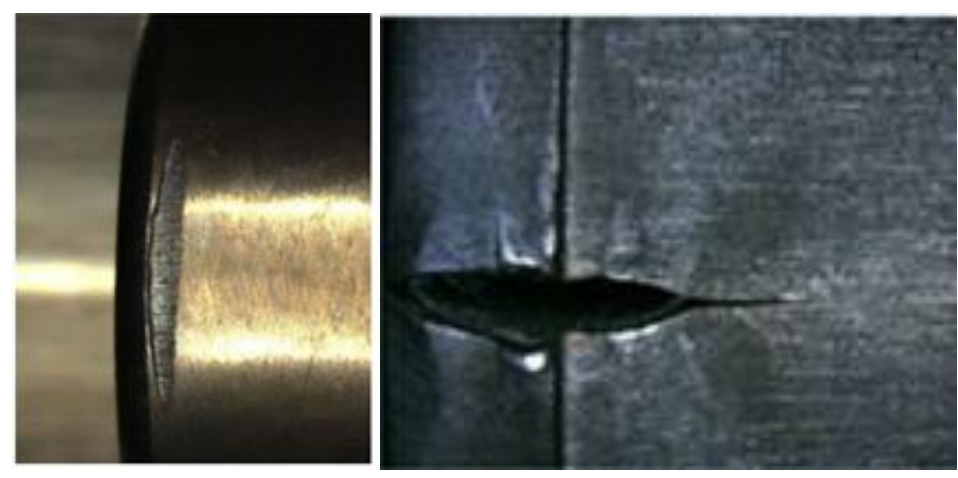

Figure 4. Chip injuries on the rollers. 


\subsection{Inproper handling}

Inproper handling of the bearing parts because of the collosion to each other and the storing box. On the surface of the rollers and inner rings dents are usually placed because of the unproper handling of the bearing elements. Mechanical damages and impacts are minimalized by using rubber plated storing boxes.
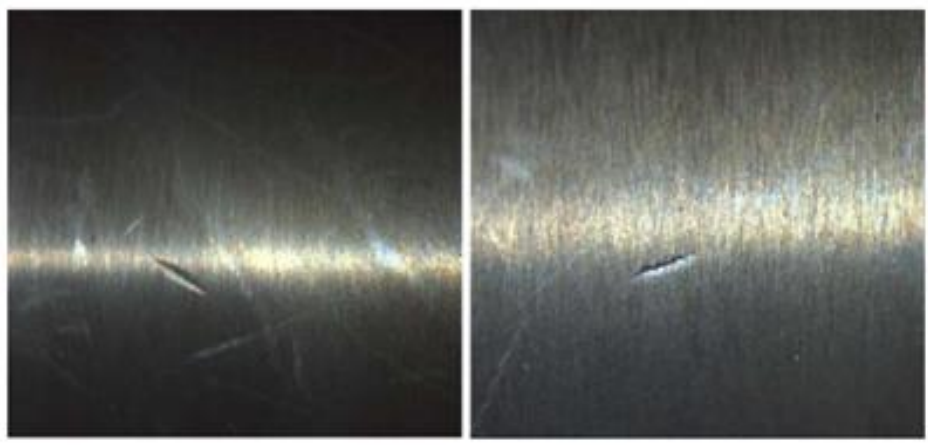

Figure 5. Dents on the rollers due to mishandling.

\subsection{Material problems}

Raw material rods sometimes have tiny cracks inside. If these cracks are not revealed properly they can cause operational problems. Eddy current measurements are generally used to investigate crack problems. Eddy current techniques are commonly used for the nondestructive examination (NDE) and condition monitoring of a large variety of metallic structures, including heat exchanger tubes, aircraft fuselage, and aircraft structural components

\section{Wavelet transform for fault detection and wavelet optimization}

Wavelet transform is continuous or discrete and it is calculated by the convolution of the signal and a wavelet function. A wavelet function is a small oscillatory wave, which contains both the analysis and the window function. Continuous wavelet transform (CWT) generates the two dimensional maps of coefficients that is called scalogram.

$$
C W T_{f}(a, b)=\frac{1}{\sqrt{a}} \int_{-\infty}^{\infty} f(t) \cdot \psi^{*}\left(\frac{t-b}{a}\right) d t
$$

where $\mathrm{a}$ is the scale parameter, $\mathrm{b}$ is the translation parameter, $\mathrm{f}(\mathrm{t})$ is the signal in time domain, $\psi$ is the 'mother' wavelet and $\psi^{*}$ is the complex conjugate of $\psi$ [19].

Discrete wavelet transform (DWT) applies filter banks for the analysis and synthesis of a signal. Filter banks contain wavelet filters and extract the frequency content of the signal in the pre-determined subbands. The discrete wavelet transform is derived from the discretization of continuous wavelet transform by adopting the dyadic scale and translation to reduce the computational time and can be expressed by the following equation [20]: 


$$
D W T_{s}(j, k)=\frac{1}{\sqrt{2^{j}}} \int_{-\infty}^{\infty} s(t) \cdot \psi^{*}\left(\frac{t-2^{j} k}{2^{j}}\right) d t
$$

where ${ }^{j}$ and ${ }^{k}$ are integers, $2^{j}$ and $2^{j} k$ represent the scale and translation parameter respectively. The original signal $s(t)$ passes through a set of low pass and high pass filters emerging as low frequency (approximations, ${ }^{a_{i}}$ ) and high frequency (details, ${ }^{d_{i}}$ ) signals at each decomposition level ${ }^{n}$. They are usually finite impulse response filters whose impulse response (or response to any finite length input) is of finite duration, because it settles to zero in finite time. Therefore, the original signal $s(t)$ can be written as [4]:

$$
s(t)=a_{n}+\sum_{i=1}^{n} d_{i}
$$

The combination of the energy and Shannon entropy content of the wavelet coefficients of the signal, denoted by Energy to Shannon Entropy ratio is an appropriate indicator to choose the best wavelet for diagnosis and it can be calculated in the following form [21, 22]:

\section{Experiment}

$$
\xi(n)=E(n) / S_{\text {entropy }}(n)
$$

In this study an experimental test rig (Fig. 6.) has been constructed to measure properly vibration signatures of the tapered roller bearings.

The shaft in the test rig is supported by two tapered roller bearings. The one under investigation is No. 30205 tapered roller bearing. Four tapered roller bearings with different manufacturing defect width on the outer race (OR1-4) were investigated in our experiments (Table 1.). Defect on the outer race is a line (rectangular) shape grinding defect (Fig. 6.) The shaft is driven by an alternating current motor of $0.75 \mathrm{~kW}$ (made by Cemer), frequency of $50 \mathrm{~Hz}$, and nominal speed of $2770 \mathrm{rpm}$ which is reduced to $1800 \mathrm{rpm}$ with variable speed drive device. Rubber V-belt between the electric engine and the shaft provides smooth running and low vibration which help accurate and precise measurements. Rubber bumpers are installed to reduce vibration of the electric motor to the bearing housing in order to minimize harmful vibrations. The arrangement provides option of different speeds controlled by Schneider ATV32HU22M2 variable speed drive device. In the experiment the speed of the shaft is measured using an optical tachometer with digital display to check the speed fluctuations. Additionally, the test rig can be used for acoustic measurements as well because an anechoic chamber is installed around the test bearing house with an appropriate features to suppress outside noises and reduce echo time. Test bearing is spanned by screw mechanism to supply the sufficient axial force to the measurements. Constant spanning force during the measurements is measured by strain gauges in Wheatstone-bride mode on the basis of difference in voltage measurement. 
NI 9234 dynamic signal acquisition is used in the experiments with 4-channels to vibration measurements from integrated electronic piezoelectric (IEPE) and non-IEPE sensors. The NI 9234 delivers $102 \mathrm{~dB}$ of dynamic range. Input channels simultaneously digitize signals at rates up to 51.2 $\mathrm{kHz}$ per channel with built-in anti-aliasing filters [17]. PCB IMI 603C01 vibration transducer is used which is an industrial type platinum stock piezoelectric sensor with low noise level, sensitivity of 100 $\mathrm{mV} / \mathrm{g}$ and frequency range of 0.27 to $10 \mathrm{kHz}$ with top exit 2-pin connector [18]. The accelerometer is placed right above the previously ground surface of the top of the bearing house with screw mechanism perpendicular to the axis of the rotation of the shaft. 32 bit AMD Athlon II X2 M300 2.0 $\mathrm{GHz}$ processor is used for data processing which is carried out in Matlab and Labview environment. For visual validation of the defect sizes on the bearing rings Garant MM1-200 video microscope is applied that is an incremental measuring system, built-in image processing with 1.3 megapixel colour camera. Furthermore, Mahr MMQ 200 with precision roundness measuring axis, motorized vertical and horizontal measuring axis is used for roundness deviation measurement to determine both width and depth of the grinding marks.

In the experiments the energy contect of the transient impulse and the signal-to-noise ratio are sufficiently large but additional effects of the structural and environmental vibrations could emerge despite of the vibration isolation system of the test rig.
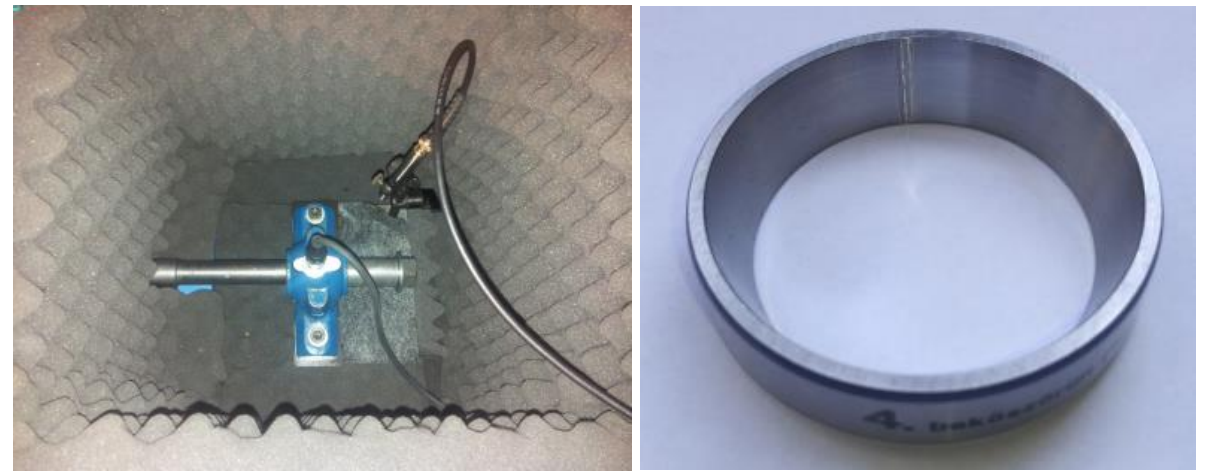

Figure 6. Test rig for tapered roller bearing measurement (left) and outer ring (OR4) (right) in the experiment.

\begin{tabular}{|c|c|c|}
\hline Type & Width $(\mathrm{mm})$ & Depth $(\mu \mathrm{m})$ \\
\hline OR1 defect & 0.6311 & 6.5 \\
\hline OR2 defect & 1.2492 & 33.6 \\
\hline OR3 defect & 1.4751 & 42.3 \\
\hline OR4 defect & 1.6236 & 51.4 \\
\hline
\end{tabular}

Table 1. Geometrical parameters of grinding defects of outer rings (OR) .

\section{Results}

\subsection{Vibration analysis}

Fig. 5. presents the spectra of outer race defect of $0.6311 \mathrm{~mm}$. The highest periodic transient impulse related energy content of the burst occurs at $2.09 \mathrm{kHz}$ that causes $5 \mathrm{~ms}$ rate of periodicity which is 
equal to $206.18 \mathrm{~Hz}$ BPFO frequency (Fig. 7.). The spectrum was measured in all outer rings with different fault sizes and they showed similar manner around the peak of $2.09 \mathrm{kHz}$.
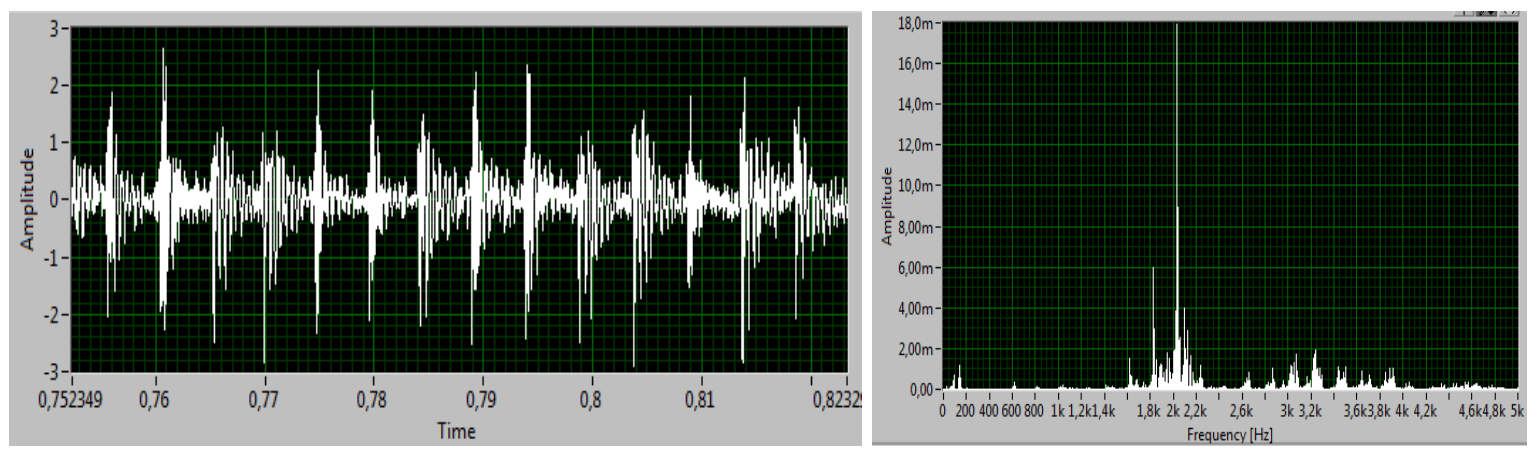

Figure 7. Typical raw time domain signal of bearing having $0.6311 \mathrm{~mm}$ of ground fault width on the outer race (left) and its spectra (rigth).

Total nine different wavelets are considered for the present study. An appropriate base wavelet should extract the maximum amount of energy, with minimizing the Shannon entropy of the corresponding wavelet coefficients. Calculated values of the Energy to Shannon Entropy ratios are in Table 2. E/S values are calculated from the vibration signal at the wavelet center of $2.08 \mathrm{kHz}$. (Table 2.).

\begin{tabular}{|l|l|c|c|c|c|c|}
\hline & E/S & OR1 & OR2 & OR3 & OR4 & Mean \\
\hline 1. & Daubechies & 57.88 & 86.55 & 117.64 & 131.78 & 98.46 \\
\hline 2. & Gaussian & 47.69 & 107.61 & 111.26 & 120.54 & 96.775 \\
\hline 3. & Coiflet & 51.23 & 62.12 & 84.78 & 91.58 & 72.4275 \\
\hline 4. & Meyer & 54.78 & 87.98 & 121.78 & 138.97 & $\mathbf{1 0 0 . 8 7}$ \\
\hline
\end{tabular}

Table 2. Calculated values of Energy to Shannon Entropy ratios of wavelet functions, $F c=2.08 \mathrm{kHz}$.

Values, after calculating the mean values of E/S ratio, are presented in Fig. 8. It is observed that Meyer wavelet gives the highest value that indicates to be the most efficient wavelet for both fault detection and possibly fault size estimation.

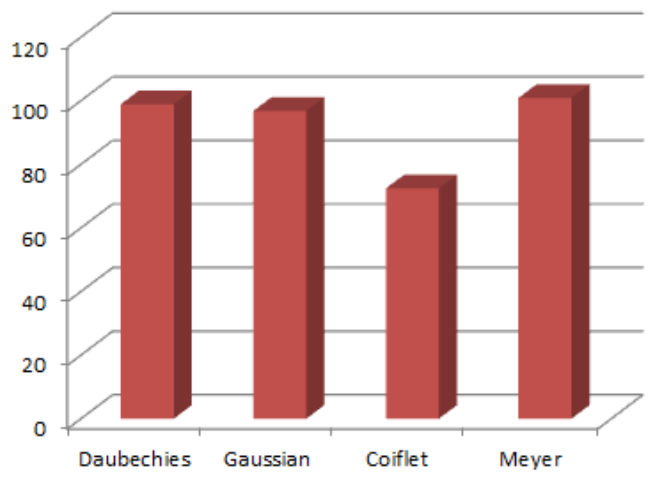

Figure 8. Energy to Shannon Entropy ratio values of wavelet functions, $F c=2.08 \mathrm{kHz}$. 


\subsection{Defects analysis with optical and semi-contact method}

Dents on the rollers are measured under microscope generally 50x magnification. Size and form of the dent is determined.

Cracks are analyzed both with microscope and Eddy current testing. For deeper analysis rollers are sometimes further investigated. Rollers should be cleaned in ultrasonic bath. They are submerged into hydrochloric acid P3 UPON 5805 4-6\% to emphasize the crack initation. 5-10 minutes are necessary to the process but longer times can cause corrosion of the $100 \mathrm{Cr} 6$ bearing steel.

Nitric acid 1-2\% was used to initate the finished surface of the roller. Then $6-10 \%$ natrium-carbonate was used to nautralize the elements. They were washed in clean water, dryed under compressied air, finally greased with Castrol DW30X material.

Rollers can be cut to see the inner cracks of the rollers. It is somestimes analysed and measured under optical microscope. After cutting the roller surface should be finished to get a very smooth surface topography. Finishing is in three steps: 80 size grinding wheel is used, then 500 size wheel, finally 1200 size wheel. One cycle is about 5 minutes wit $50 \mathrm{~N}$ pushing force. Final step is to place them in special DuroFast bacelit powder that is heat treated to get solid state.
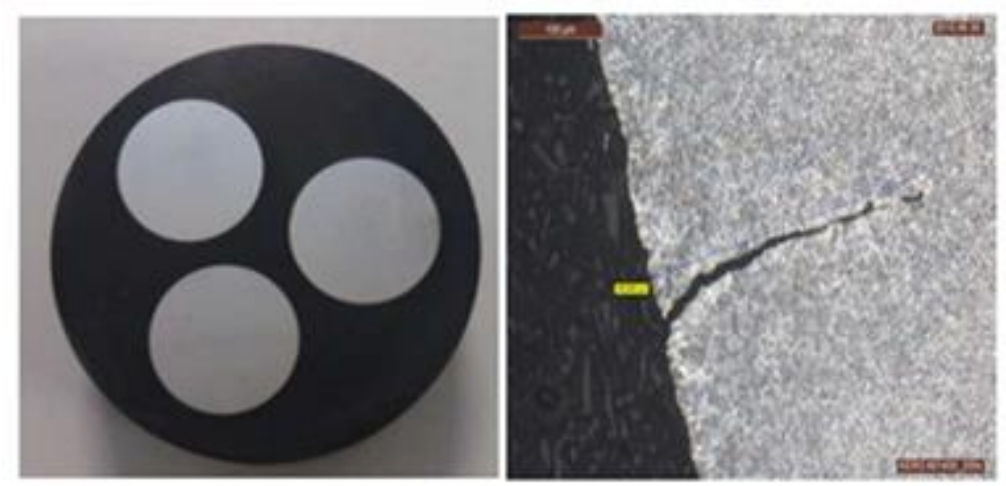

Figure 9. Embedded rollers (left) and cracks of the roller under 50x optical microscope (right).

Leica optical microscope was used in our experiment to measure the inner crack size. 240 rollers were analyzed from the previously Eddy current investigated rollers which were identified as bad quality rollers with inner cracks. $87 \%$ of the rollers had cracks inside. The average size of the cracks is 240,78 um, from 138,7 um to 442,9 um. Mahr Perthometer was used to measure the surface injuries (Figure 10-11.).

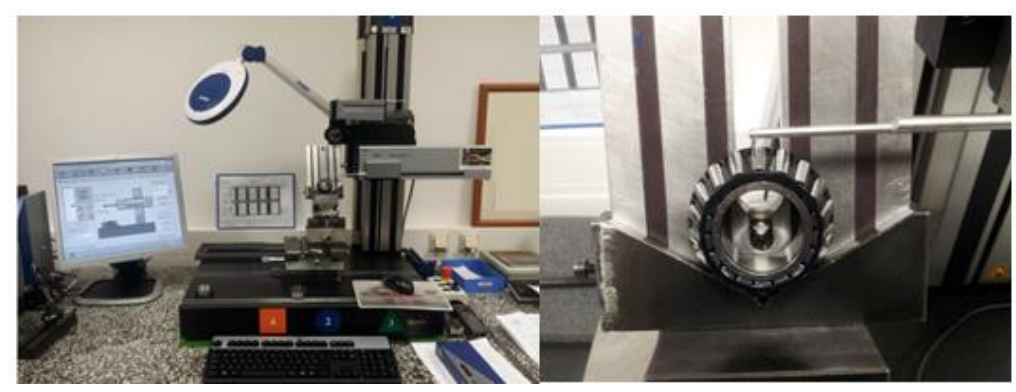

Figure 10. Mahr Perthometer (left) and semi-contact measurements of surface faults (right). 


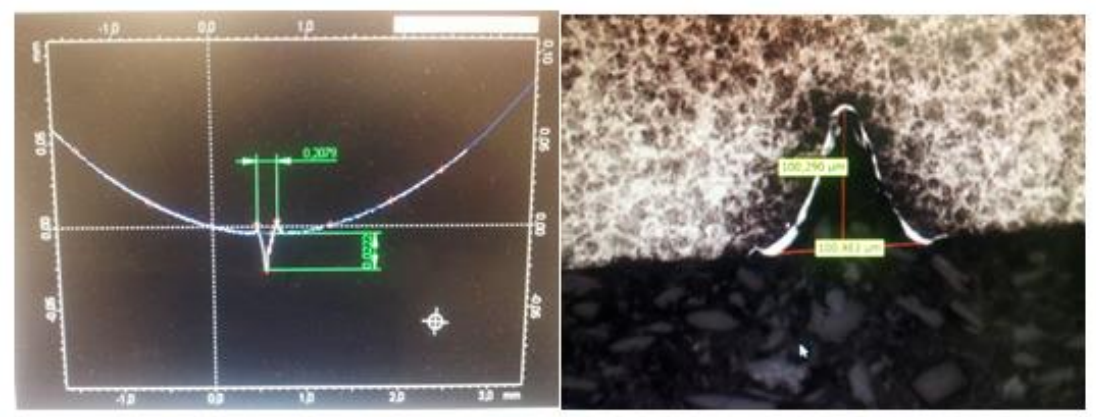

Figure 11. Inner crack dimension measurement with Mahr Perthometer (left) and optical microscope (right).

Mechanical injuries of the machine parts cause excessive vibration of the bearing. Bearings are further measured with vibration transducers and DAQ systems with Fourier transform in bearing manufacturing. These measurements are presented other papers of the authors.

\section{Conclusions}

Manufacturing problems are from grinding defects, chatter vibration, irregular shape of grinding stone due to tool wear process and tool misalignment, pulling and squeezing operations. Improper handling of bearing elements could emerge when rings and rolling elemenst suffer plastic deformation such us dents and mechanical irregularities. Sources were revealed and analyzed by Ishikawa diagram. It is clear that beside human and environmental factors, machine and technology have a great influence on bearing quality. Visual inspection by optical devices can be efficiently applied to validate the outside faults. For analyzing inner cracks it was good result by cutting the rollers then handled by acids and placed, reinforced in test specimens. It is clear that constant development of technological processes is absolutely necessary in bearing manufacture. Wavelet analysis is an efficient method to detect sharp edges in the vibration signal generated by tiny defects which emerge in the form of transient impulses. Wavelet transform using four different real-valued wavelets has been proposed for measuring outer race manufacturing defect width of tapered roller bearings. The best wavelet was chosen by Shannon Entropy Criteria creates the opportunity to determine the manufacturing defect width in the most accurate way because it presents the best correlation with the transients. Methods gave sufficient results for detecting manufacturing faults in the experiments.

\section{Acknowledgement}

The publication is supported by the EFOP-3.6.1-16-2016-00022 project. The project is co-financed by the European Union and the European Social Fund.

\section{References}

[1] Patel, V. N., Tandon, N., Pandey, R., K. (2012), Defect Detection in Deep Groove Ball Bearing in Presence of External Vibration Using Envelope Analysis and Duffing Oscillator. Measurement, vol. 45, p. 960. 
[2] Khanam, S., Tandon, N., Dutt, J. K. (2012), Fault Identification of Rolling Element Bearings from Vibration Signals: An Application of Kalman and H Filters. LOWHUV 10th International Conference on Vibrations in Rotating Machinery (VIRM10), p. 703-713.

[3] Al-Ghamd, A.M., Mba, D. (2006), A Comparative Experimental Study on the Use of Acoustic Emission and Vibration Analysis for Bearing Defect Identification and Estimation of Defect Size, Mechanical Systems and Signal Processing, vol. 20, p. 1537.

[4] Elforjani, M., Mba, D. (2010), Accelerated Natural Fault Diagnosis in Slow Speed Bearings with Acoustic Emission. Engineering Fracture Mechanics, vol. 77, p. 112.

[5] Sawalhi, N., Randall, R.B. (2011), Vibration Response of Spalled Rolling Element Bearings: Observations, Simulations and Signal Processing Techniques to Track the Spall Size. Mechanical Systems and Signal Processing, vol. 25, p. 846.

[6] Peng, Z.K., Chu, F.L. (2004), Application of the Wavelet Transform in Machine Condition Monitoring and Fault Diagnostics. Mechanical Systems and Signal Processing, vol. 18, p. 199.

[7] Prabhakar, S., Mohanty, A.R., Sekhar, A.S. (2002), Application of Discrete Wavelet Transform for Detection of Ball Bearing Race Faults. Tribology International, vol. 35, p.793.

[8] Shi, D. F., Wang, W. J., and Qu, L. S. (2004), Defect detection for bearings using envelope spectra of wavelet transform. ASME Journal of Vibration and Acoustics, vol. 126, no. 4, p. 567.

[9] Nikolaou, N. G., Antoniadis, I. A. (2002), Demodulation of Vibration Signals Generated by Defects in Rolling Element Bearings Using Complex Shifted Morlet Wavelets. Mechanical Systems and Signal Processing, vol. 16, no. 4, p. 677.

[10] Qiu, H., Lee, J., Lin, J., Yu, G. (2006), Wavelet Filter-Based Weak Signature Detection Method and its Application on Rolling Element Bearing Prognostics. Journal of Sound and Vibration, vol. 289, p. 1066.

[11] Junsheng, C., Dejie, Y., Yu, Y. (2007), Application of an Impulse Response Wavelet to Fault Diagnosis of Rolling Bearings. Mechanical Systems and Signal Processing, vol. 21, p. 920.

[12] Kumar, R., Singh, M. (2013), Outer Race Defect Width Measurement in Tapered Roller Bearing using Discrete Wavelet Transform of Vibration Signal. Measurement, vol. 46, p. 537.

[13] Awal, M. A., Mostafa, S. S., Ahmad, M. (2012), Quality Assessement of ECG Signal Using Symlet Wavelet Transform. Proceedings of International Conference on Advances in Electrical Engineering, p.129-134.

[14] Chavan, M. S., Mastorakis, N., Chavan, M. N., Gaikwad, M. S. (2012), Implementation of SYMLET Wavelets to Removal of Gaussian Additive Noise from Speech Signal. Recent Researches in Communications, Automation, Signal Processing, Nanotechnology, Astronomy and Nuclear Physics, p. 37-41. 
[15] Kumar, R., Jena, D.P., Bains, M. (2010), Identification of inner race defect in radial ball bearing using acoustic emission and wavelet analysis. Proceedings of ISMA 2010 including USD 2010 Leuven (Belgium), p. 2883-2891.

[16] Mankovits, T., Szabó, T., Kocsis, I., Páczelt, I. (2014), Optimization of the Shape of AxiSymmetric Rubber Bumpers. Strojniski vestnik-Journal of Mechanical Engineering, vol. 60, no. 1, p. 61-71.

[17] NI 9234 datasheet: http://www.ni.com/datasheet/pdf/en/ds-316, accessed on 2016-0204.

[18] PCB IMI 603C01 transducer, from https://www.pcb.com/contentstore/docs/PCB_Corporate/IMI/Products/Manuals/603C0 1.pdf, accessed on 2016-02-04.

[19] Michel Misiti, Yves Misiti, Georges Oppenheim, Jean-Michel Poggi (2007), Wavelets and their Applications. ISTE Ltd.

[20] Salguerio, J., Persin, G., Vizintin, J., Ivanovic, M., Dolenc, B. (2013), On-line Oil Monitoring and Diagnosis. Strojniski vestnik-Journal of Mechanical Engineering, vol. 59, no. 10, p. 604612.

[21] Kankar, P.K., Sharma, S.C., Harsha, S.P. (2011), Fault diagnosis of ball bearings using continuous wavelet transform. Applied Soft Computing, vol. 11, p. 2300-2312.

[22] Kankar, P.K., Sharma, S.C., Harsha, S.P. (2013), Fault diagnosis of rolling element bearing using cyclic autocorrelation and wavelet transform. Neurocomputing, vol. 110, p. 9-17.

[23] Szántó, A., Szíki, G., Hajdu, S. (2016), Elektromos hajtású tanszéki versenyautó jármúdinamikai modellezése, Vehicle dynamics modelling of an electric driven race car. IJEMS 1 (2), 106-114.

[24] Szántó, A., Szíki, G., Hajdu, S., Gábora, A. (2017), Soros gerjesztésű egyenáramú motor szimulációja MATLAB környezetben, Simulation of a Series Wound DC Motor in MATLAB Environment. In: A XXII. Fiatal Műszakiak Tudományos Ülésszak előadásai = Proceedings of the XXII-th International Scientific Conference of Young Engineers / szerk. Bitay Enikő, Erdélyi Múzeum Egyesület (EME), Kolozsvár, 367-370.

[25] Krisztián Deák, Tamás Mankovits, Imre Kocsis (2017), Optimal wavelet selection for manufacturing defect size estimation of tapered roller bearings with vibration measurement using Shannon Entropy Criteria, Strojniski vestnik-journal of mechanical engineering 63:(1) pp. 3-14.

[26] Attila Vámosi, Tamás Mankovits, Dávid Huri, Imre Kocsis, Tamás Szabó (2015), Comparison of Different Data Acquisition Techniques for Shape Optimization Problems International journal of mechanical aerospace industrial mechatronic and manufacturing engineering 9:(3) pp. 409-412 
[27] Mankovits Tamás, Szabó Tamás, Kocsis Imre, Páczelt István (2014), Optimization of the Shape of Axi-Symmetric Rubber Bumpers, Strojniski vestnik-journal of mechanical engineering 60:(1) pp. 61-71.

[28] Kocsis Imre, Mankovits Tamás (2013), Application of Non-parametric Regression in Engineering Optimization, Analele universitatii din oradea fasciola management si inginerie tehnologica / annals of the university of oradea fascicle of management and technological engineering 12:(22) pp. 159-162.

[29] Mankovits Tamás, Kocsis Imre, Portik Tamás, Szabó Tamás, Páczelt István (2013), Shape Design of Rubber Part Using FEM, International review of applied sciences and engineering 4:(2) pp. 85-94. 